\title{
Soil Erosion Is Influenced by Grain for Green Policy in Loess Plateau Area of Northern Shaanxi, China
}

\author{
Tao Wang \\ College of Geomatics, Xi'an University of Science and Technology, Xi'an, China
}

Email address:

wht432@163.com

To cite this article:

Tao Wang. Soil Erosion Is Influenced by Grain for Green Policy in Loess Plateau Area of Northern Shaanxi, China. International Journal of Environmental Protection and Policy. Vol. 3, No. 5, 2015, pp. 129-136. doi: 10.11648/j.ijepp.20150305.13

\begin{abstract}
Grain for Green Policy (GGP), one of China's important ecological construction and protection policies, have been made remarkable achievements since implementation in 1999. The purpose of this work is to assessment of soil erosion influenced by GGP, which implementation is lead to great change of land use and vegetation cover, using RUSLE model on the basis of land use, MODIS NDVI, DEM and precipitation data in Loess Plateau area of northern Shaanxi, northwest of China. Result showed: (1) GGP implementation in northern Shaanxi was mainly during 1999-2003 and the area of returning farmland in the period accounted for $81.28 \%$ of the total area from 1999 to 2008 . (2) Farmland in northern Shaanxi and slope $>25^{\circ}$ was decrease $4.94 \%$ and $4.84 \%$, respective ly, while grassland was increase $4.04 \%$ and $4.05 \%$, respectively. The change of decreasing farmland and increasing grassland was mainly from 2000 to 2005 in northern Shaanxi and slope $>25^{\circ}$. (3) Farmland was convert into woodland and grassland, which leaded to increasing of vegetation NDVI. Especially, the vegetation NDVI value of farmland in slope $>25^{\circ}$ was increase larger than whole area of northern Shaanxi from 2000 to 2010. (4) The change area of soil erosion in northern Shaanxi and slope $>25^{\circ}$ was decrease in 1 degree, while was increase in other degrees from 2000 to 2010 . But when recalculated by rainfall erosivity in 2000, the change area of soil erosion in northern Shaanxi and $>25^{\circ}$ was increase in 1 degree, while was decrease in other degrees from 2000 to 2010 . Vegetation cover change induced by GGP was reduce soil erosion, but due to rainfall erosivity increased, soil erosion was show increase trend in northern Shaanxi and slope $>25^{\circ}$.
\end{abstract}

Keywords: Land Use Change, MODIS NDVI, Rainfall Erosivity, Loess Plateau

\section{Introduction}

Grain for Green Policy (GGP) is one of the major ecological protection and construction policies in China. GGP pilot implementation involve 1897 county-level administrative units since 1999, and those counties included in loess plateau area of northern Shaanxi province are key counties of construction. By 2010, the area of returning farmland to forest was $906.30 \times 10^{4} \mathrm{hm}^{2}$, afforestation of barren hills was $1533.97 \times 10^{4} \mathrm{hm}^{2}$, new forest conservation was $246.81 \times 10^{4} \mathrm{hm}^{2}$, total food subsidies was $\$ 322.79 \times 10^{8}(\$ 1=Y 6)$, and subsidies of living cash amounting was $\$ 43.74 \times 10^{8}[1]$. With the implementation of GGP, forest cover rate has been improved, and GGP has achieved significant environment benefits [2].

Loess Plateau area in northern Shaanxi province is a serious soil erosion area, and the key area of GGP implementation. Affected by GGP, ecological environment has been improved obviously, vegetation cover increased, land use structure adjusted, a large area of arable land on steep slopes has been converted into forest or grassland, soil nutrients has been recovered and soil erosion decreased in northern Shaanxi $[3,4]$. Implementation of GGP was lead to reduction of arable land, promotion of rural surplus labor to non-agricultural industries, and improved of rural household's economic structure [5]. By the impact of GGP, total arable land of grain output was declined but grain yield of per unit area was increased [6,7]. Overall, ecological environment - human social system had been changing in many aspects by GGP. By the continued implementation of GGP, issues of implementation were highlighted by scholars [8].

Vegetation cover are important factors affecting soil erosion $[9,10,11]$. The goal of GGP implementation in northern Shaanxi is to reduce soil erosion. Relevant regulations and laws required the farmland which has serious soil erosion, important ecological status but low grain production, should be included in GGP plans and is prohibited reclamation in slope $>25^{\circ}$ area. Therefore, even though the policy does not explicit propose, but the arable land especially in slope $>25^{\circ}$ should be the main target of GGP $[4,12]$. The purpose of this work is to assessment 
of soil erosion influenced by GGP, which implementation is lead to great change of land use and vegetation cover, using RUSLE model on the basis of land use, MODIS NDVI, DEM and precipitation data in Loess Plateau area of northern Shaanxi, northwest of China.

\section{Materials and Methods}

\subsection{Study Area}

Loess plateau area in northern Shaanxi include Yulin and Yan'an, which contain 25 countries and locate in $107^{\circ} 15^{\prime} 56^{\prime \prime} \mathrm{E}-111^{\circ} 13^{\prime} 10^{\prime \prime} \mathrm{E}$ and $35^{\circ} 21^{\prime} 56^{\prime \prime} \mathrm{N}-39^{\circ} 35^{\prime} 06^{\prime \prime} \mathrm{N}$ (Figure.1), while Mu Us Sand land along the edge of northern Yulin. By the end of 2011, the total population of the area is $554.64 \times 10^{4}$, and the total land area is $80624 \mathrm{~km}^{2}$. The climate is temperate continental monsoon climate, and the average temperature is $9.5^{\circ} \mathrm{C}$. Annual average rainfall and the average sunshine are $506.5 \mathrm{~mm}$ and $2540 \mathrm{~h} / \mathrm{a}$, respectively, and frost-free period is $194 \mathrm{~d}$. The whole territory belongs to the Yellow River watershed, and the main tributary is Wuding River and Yanhe River, etc [13].

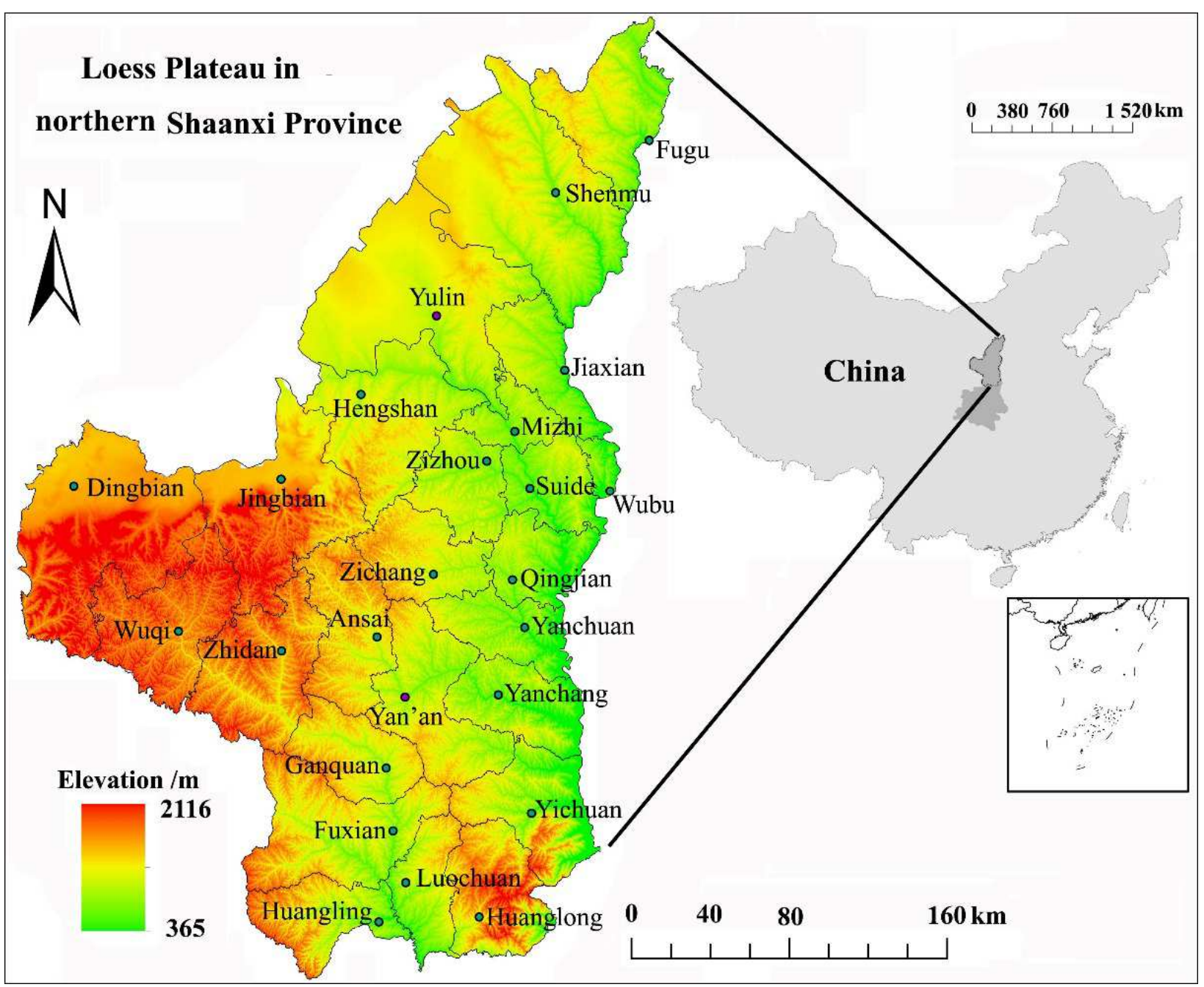

Figure 1. Study area.

Precipitation in study area is focus on the summer and autumn, which account for $80 \%$ of annual precipitation, and which also the important reasons of soil erosion in northern Shaanxi, China. Yulin and Yan'an are the mainly area of GGP implementation in Shaanxi province. According to the statistical yearbook of Shaanxi province (1999-2008), the area of returning farmland to forest in northern Shaanxi is $472.1 \times 10^{3} \mathrm{hm}^{2}$ from 1999 to 2008 , accounting for $41.14 \%$ of total area of returning farmland to forest in Shaanxi province [13].

\subsection{Materials}

The data used in this research include: (1) 1:100 000 vector land use map of northern Shaanxi in 2000, 2005 and 2010 year, comes from the project "Remote sensing survey and evaluation of ecological environment change in China (2000-2010)". Land use map in 2010 was classified by environmental satellite images, while TM images were used in 2000 and 2005. Geographic coordinates of land use map is GCS WGS84, and projection is Albers ellipsoid with central longitude $105^{\circ}$. Classification system of land use map include 
7 primary classifications and 30 secondary classifications. (2) Vector county administrative boundary map of northern Shaanxi. (3) ASTER GDEM data with $30 \mathrm{~m}$ resolution of northern Shaanxi. The dataset was provided by Geospatial Data Cloud, Computer Network Information Center, Chinese Academy of Sciences (http://www.gscloud.cn). (4) Daily rainfall data of 7 stations from 1991 to 2010 is collected from China Meteorological Data Sharing Service System (http://cdc.nmic.cn). The station is Dingbian, Yulin, Hengshan, Suide, Wuqi, Yan'an and Luochuan. (5) Soil map of northern Shaanxi with scale of 1:500 000. (6) MODIS NDVI 13Q1-Level 3 images data of vegetation index with $250 \mathrm{~m}$ resolution of northern Shaanxi in 2000, 2005 and 2010. (7) Shaanxi statistical yearbook from 2001 to 2011.

\subsection{Methods}

The Revised Universal Soil Loss Equation (RUSLE) is used to calculate soil erosion of northern Shaanxi. RUSLE is represented as follows [14]

$$
\mathrm{A}=\mathrm{R} \times \mathrm{K} \times \mathrm{L} \times \mathrm{S} \times \mathrm{C} \times \mathrm{P}
$$

where $A$ is the amount of the average soil loss $\left(\mathrm{t} \cdot \mathrm{hm}^{-2} \cdot \mathrm{a}^{-1}\right) ; R$ is the rainfall erosivity factor $\left(\mathrm{MJ} \cdot \mathrm{mm} \cdot \mathrm{hm}^{-2} \cdot \mathrm{h}^{-1} \cdot \mathrm{a}^{-1}\right) ; K$ is the soil erodibility factor $\left(\mathrm{t} \cdot \mathrm{hm}^{-2} \cdot \mathrm{h} \cdot \mathrm{hm}^{-2} \cdot \mathrm{MJ}^{-1} \cdot \mathrm{mm}^{-1}\right) ; L$ is the slope length factor; $S$ is the slope factor; $C$ is the vegetation cover factor and $P$ is the erosion control practice factor.

$$
K=\left(0.2+0.3 \exp \left(0.0256 M\left(1-\frac{F}{100}\right)\right)\right) \cdot\left(\frac{F}{N+F}\right)^{0.3}
$$

where, $M, F, N$ is mass fraction of sand, silt and clay, respectively, \%; $T$ is mass fraction of soil organic carbon, $\%$; $\delta=1-M / 100$. The $K$ value is need to change into the international system of units through multiplied by 0.1317 , $\mathrm{t} \cdot \mathrm{hm}^{2} \cdot \mathrm{h} / \mathrm{hm}^{2} \cdot \mathrm{MJ} \cdot \mathrm{mm}$.

\subsubsection{Topographical Factor (LS)}

Slope and slope length $(L S)$ are topographical factor, which mainly reflecting the effects of topography on soil erosion. $L$ is calculated by DEM according to [21] proposed formula and $S$ is calculated by the formula proposed by [22] and [23]. The formula is expressed as follows:

$$
\begin{gathered}
L=(\lambda / 22.13)^{\alpha} \\
\alpha=\beta(\beta+1), \beta=(\sin \theta / 0.0896) /\left(3.0(\sin \theta)^{0.8}+0.56\right) \\
S=\left\{\begin{array}{c}
10.8 \sin \theta+0.03, \theta<9 \% \\
16.8 \sin \theta-0.50,9 \% \leq \theta<14 \% \\
21.9 \sin \theta-0.96, \theta \geq 14 \%
\end{array}\right.
\end{gathered}
$$

where $\lambda$ is the slope length; $\alpha$ is the slope length index; $\theta$ is the slope (\%) extract by DEM.

\subsubsection{Vegetation Cover Factor (C)}

$C$ factor is vegetation index, which is calculated based on MODIS NDVI data, the formula is expressed as follows [24,25]:

$$
\text { AVHRR NDVI }=0.18 M O D I S N D V I+0.131
$$

\subsubsection{Rainfall Erosivity Factor (R)}

$R$ factor is the indicator for evaluating the impact of rainfall on soil separation and transportation, and is used to estimate by rainfall parameters. Annual rainfall erosivity is calculated by daily rainfall data proposed by $[15,16]$ :

$$
\begin{gathered}
R_{i}=\alpha \sum_{j=1}^{k} P_{j}^{\beta} \\
\alpha=21.586 \beta^{-7.1891} \\
\beta=0.8363+18.144 P_{d 12}^{-1}+24.455 P_{y 12}^{-1}
\end{gathered}
$$

where $R_{i}$ is the rainfall erosivity of $i$ th year, $\mathrm{MJ} \cdot \mathrm{mm} \cdot \mathrm{hm}^{-2} \cdot \mathrm{h}^{-1} \cdot \mathrm{a}^{-1} ; k$ is the number of days with erosive rainfall in one year, $\mathrm{d}$; and $P_{j}$ is the erosive rainfall of $j$ th day, $\mathrm{mm}$. The standard rainfall leading to soil erosion is $\geq 12 \mathrm{~mm} / \mathrm{d}$, otherwise is calculated by 0 value [17]. $\alpha$ and $\beta$ are characteristic parameters, and $P_{d 12}$ is annual average daily rainfall with daily rainfall $\geq 12 \mathrm{~mm}, \mathrm{~mm}$, while $P_{y / 2}$ is average annual rainfall of rainfall $\geq 12 \mathrm{~mm}, \mathrm{~mm}$.

\subsubsection{Soil Erodibility Factor (K)}

$K$ factor affected by many factors, is the indicator to evaluate soil erosion probability when rainfall erosivity is occurred $[18,19]$. $K$ value is calculated by EPIC model $[20]$ as follows:

$$
\begin{gathered}
\left(1.0-\frac{0.25 T}{T+\exp (3.72-2.95 T)}\right) \cdot\left(1.0-\frac{0.7 \delta}{\delta+\exp (-5.51+22.9 \delta)}\right) \\
C=\exp \left(-\alpha \cdot \frac{A V H R R N D V I}{\beta-A V H R R N D V I}\right)
\end{gathered}
$$

where $\alpha$ and $\beta$ are parameters with the value of 2 and 1, respectively. $C$ value is calculated by AVHRR NDVI data, which need to covert MODIS NDVI into AVHRR NDVI.

\subsubsection{Erosion Control Practice Factor (P)}

$P$ factor is calculated by the following formula proposed by [26]:

$$
P=0.2+0.03 \mathrm{~S}
$$

where $S$ is the slope extracted by DEM (\%).

\section{Results}

\subsection{GGP on Land Use Change}

\subsubsection{Decreased Area of GGP Implementation in Northern Shaanxi}

The area of returning farmland to forest or grassland of Shaanxi province and northern Shaanxi region including Yan'an and Yulin city was obtained by statistical yearbook of Shaanxi province from 2000 to 2011, and the result showed in Figure.2.

GGP implementation was occurred mainly during 1999-2008, and statistical yearbook of Shaanxi province was not recorded about the area of returning farmland to forest or grassland after 2009. From 1999 to 2008 of GGP 
implementation, the area of returning farmland was about $11476.2 \mathrm{~km}^{2}$ in Shaanxi province, where the area of returning farmland in northern Shaanxi (Yulin and Yan'an) was $4721 \mathrm{~km}^{2}$, accounting for $41.14 \%$.

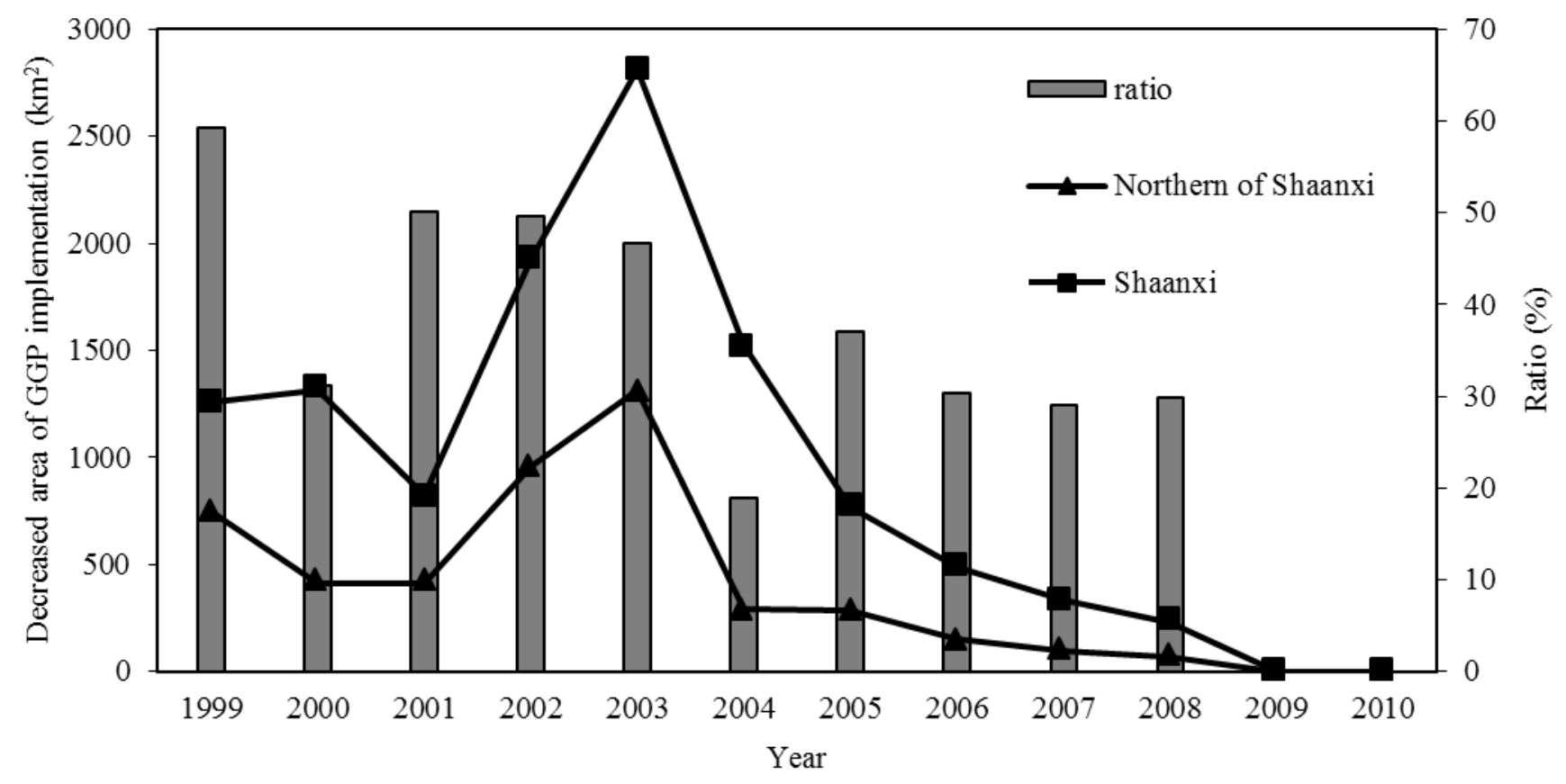

Figure 2. Decreased area of GGP implementation in Shaanxi province and northern Shaanxi.

The process of area change can be divided into 2 stages. The first stage was from 1999 to 2003 with increasing trend of area of returning farmland in Shaanxi province and northern Shaanxi, and the ratio of returning farmland area in northern Shaanxi accounting for Shaanxi province was higher than $40 \%$ (except in 2000). The second stage was from 2003 to 2008 with decreasing trend of area of returning farmland in Shaanxi province and northern Shaanxi, and the ratio of returning farmland area in northern Shaanxi accounting for Shaanxi province was about 30\% (except in 2004).

Overall, GGP implementation in northern Shaanxi was mainly during 1999-2003, and the area of returning farmland

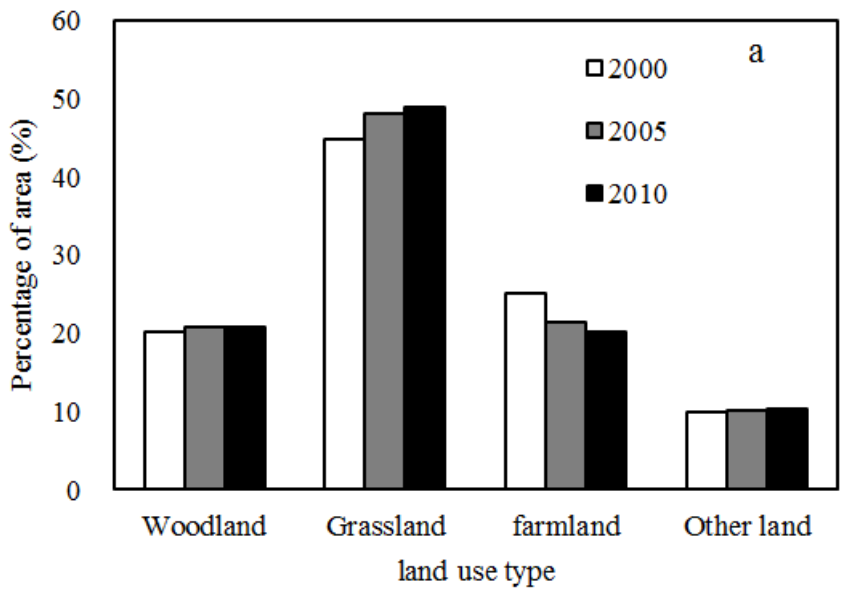

in the period accounting for $81.28 \%$ of the total area during 1999-2008.

\subsubsection{Land Use Change}

Land use type in northern Shaanxi was woodland, grassland and farmland, which three land types accounting for more than $90 \%$ of the total land area. Woodland and grassland were show an increasing trend and the percentage increased from $20.21 \%$ to $20.73 \%$, from $44.74 \%$ to $48.78 \%$, respectively, during 2000-2010, while farmland showed decreasing trend and the percentage decreased from $25.16 \%$ to $20.22 \%$ (Figure.3a).

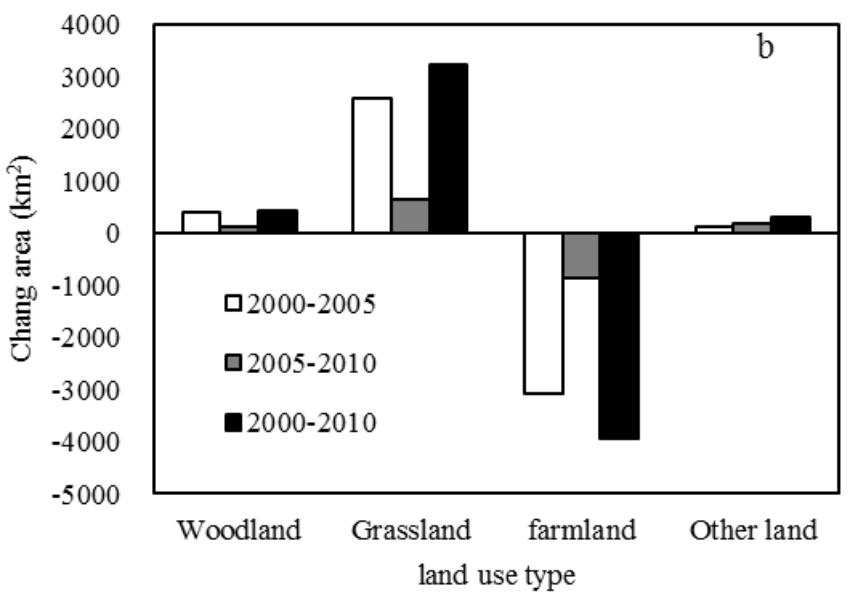

Figure 3. Land use structure (a) and change area (b) in different stage of northern Shaanxi.

Woodland, grassland and farmland were the largest types of land use change. The area of woodland and grassland were increase $412.35 \mathrm{~km}^{2}$ and $3229.71 \mathrm{~km}^{2}$, respectively, from 2000 to 2010 , while farmland was decrease $3948.16 \mathrm{~km}^{2}$ (Figure. $3 \mathrm{~b}$ ). The change rate of woodland, grassland and farmland were $0.52 \%, 4.04 \%$ and $-4.94 \%$, respectively, during $2000-2010$. 
The most intense period of land use change was from 2000 to 2005 in northern Shaanxi. In the period of 2000-2005, the change area of woodland, grassland and farmland were $377.49 \mathrm{~km}^{2}, 2583.13 \mathrm{~km}^{2}$ and $-3081.71 \mathrm{~km}^{2}$, respectively, and accounting for $91.55 \%, 79.98 \%$ and $78.05 \%$ of the total change area of 2000-2010, respectively.

\subsubsection{Land Use Change in Slope $>25^{\circ}$}

Land use type in slope $>25^{\circ}$ of northern Shaanxi was

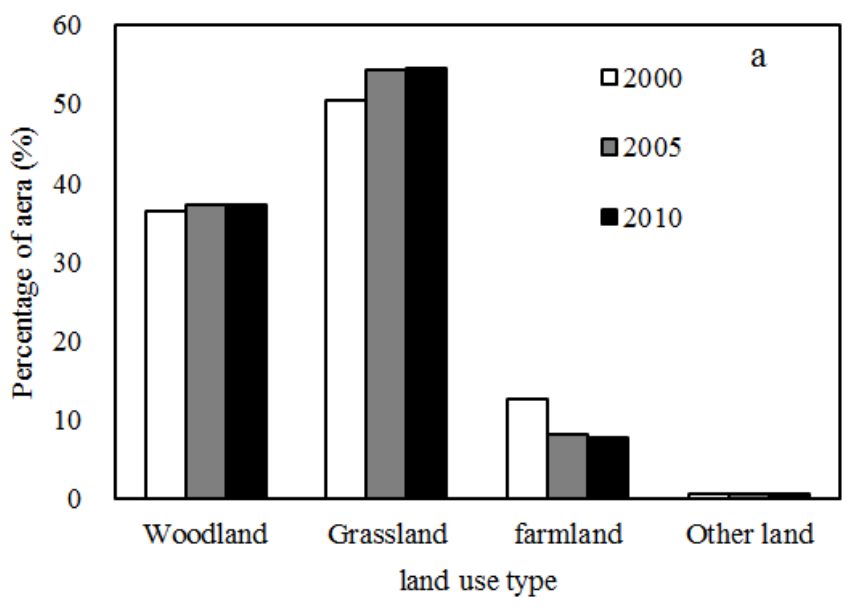

woodland, grassland and farmland, which three land types accounting for more than $99 \%$ of the total land area in slope $>25^{\circ}$. Woodland and grassland were show an increasing trend and the percentage increased from $36.47 \%$ to $37.17 \%$, from $50.50 \%$ to $54.55 \%$, respectively, during $2000-2010$, while farmland showed decreasing trend and the percentage decreased from $12.59 \%$ to $7.75 \%$ (Figure.4a).

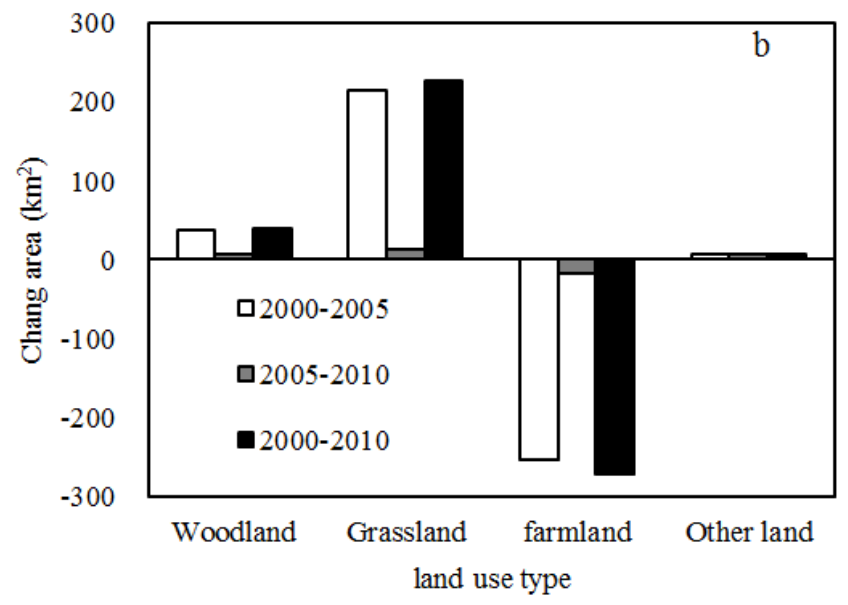

Figure 4. Land use structure (a) and change area (b) in different stage of slope $>25^{\circ}$ in northern Shaanxi.

Woodland, grassland and farmland were the largest types of land use change in slope $>25^{\circ}$. The area of woodland and grassland were increase $39.51 \mathrm{~km}^{2}$ and $226.90 \mathrm{~km}^{2}$, respectively, from 2000 to 2010, while farmland was decrease $270.67 \mathrm{~km}^{2}$ (Figure.4b). The change rate of woodland, grassland and farmland were $0.70 \%, 4.05 \%$ and $-4.84 \%$, respectively, during 2000-2010.

The most intense period of land use change in slope $>25^{\circ}$ was from 2000 to 2005 in northern Shaanxi. In the period of 2000-2005, the change area of woodland, grassland and farmland were $38.41 \mathrm{~km}^{2}, 213.65 \mathrm{~km}^{2}$ and $-254.04 \mathrm{~km}^{2}$, respectively, and accounting for $97.21 \%, 94.16 \%$ and $93.86 \%$ of the total change area of 2000-2010, respectively.

\subsection{GGP on Vegetation Cover Change}

Large changes of land use were happened in northern Shaanxi by GGP implementation, which also lead to changes of vegetation cover. Land use and vegetation NDVI data were used to extract vegetation NDVI value corresponding to 2000, 2005 and 2010 of farmland area in 2000 in northern Shaanxi and slope $>25^{\circ}$, and the value of vegetation NDVI of changed and unchanged area of farmland in 2000. Results show in Table 1.

Table 1. Vegetation NDVI value in different area.

\begin{tabular}{|c|c|c|c|c|c|c|c|}
\hline & Type & 2000 & 2005 & 2010 & $2000-2005$ & 2000-2010 & $2000-2010(\%)$ \\
\hline \multirow{3}{*}{ Farmland area } & 2000 & 0.4111 & 0.5053 & 0.5623 & 0.0942 & 0.1512 & 36.78 \\
\hline & Unchanged during 2000-2010 & 0.4152 & 0.5034 & 0.5565 & 0.0882 & 0.1413 & 34.03 \\
\hline & Changed during 2000-2010 & 0.3947 & 0.5129 & 0.5859 & 0.1182 & 0.1912 & 48.44 \\
\hline \multirow{3}{*}{ Farmland area in slope $>25^{\circ}$} & 2000 & 0.4074 & 0.5197 & 0.5856 & 0.1123 & 0.1782 & 43.74 \\
\hline & Unchanged during 2000-2010 & 0.4035 & 0.5024 & 0.5630 & 0.0989 & 0.1595 & 39.53 \\
\hline & Changed during 2000-2010 & 0.4135 & 0.5468 & 0.6210 & 0.1333 & 0.2075 & 50.18 \\
\hline
\end{tabular}

The direct effect of GGP implementation was lead to a significant reduction of farmland converting to woodland and grassland, thereby vegetation NDVI value increased. The vegetation NDVI value of farmland area in 2000 showed increasing trend from 2000 to 2010 , with an increase of 0.1512 which accounting for $36.78 \%$ of 2000 . In the farmland area of 2000 , the vegetation NDVI of farmland unchanged area was increase 0.1413 with $34.03 \%$ while of farmland changed area increased 0.1912 with $48.44 \%$ (Table 1). Therefore, the vegetation NDVI of changed area of farmland in 2000 was increase larger than the vegetation value of unchanged area, which was influenced by GGP implementation.

The vegetation NDVI value of farmland area in slope $>25^{\circ}$ in 2000 showed increasing trend from 2000 to 2010, with an increase of 0.1782 which accounting for $43.74 \%$ of 2000 . In the farmland area of slope $>25^{\circ}$ in 2000 , the vegetation NDVI of farmland unchanged area was increase 0.1595 with $39.53 \%$ while of farmland changed area increased 0.2075 with $50.18 \%$ (Table 1).

Overall, farmland was convert into woodland and grassland 
from 2000 to 2010, which leaded to vegetation NDVI increase by GGP implementation. Especially, the vegetation NDVI value of farmland in slope $>25^{\circ}$ was increase more than whole area of northern Shaanxi.

\subsection{GGP on Soil Erosion}

The value of $R, K, L, S, P$ and $C$ was calculated by the formula mentioned in the context. $R$ and $C$ had different value in 2000, 2005 and 2010, so the amount of the average soil loss in northern Shaanxi and the area of slope $>25^{\circ}$ were obtained in 2000, 2005 and 2010. While for evaluating GGP on soil erosion, the rainfall erosivity should be not considered. Therefore, the amount of the average soil loss in northern Shaanxi and the area of slope $>25^{\circ}$ were also obtained in 2000 , 2005 and 2010 using the rainfall erosivity of 2000. Six soil erosion degree was divided according to the classify standard of soil erosion [27], that was 1, 2, 3, 4, 5, 6 degree with the amount of the average soil loss $<1000 \mathrm{t} \cdot \mathrm{hm}^{-2} \cdot \mathrm{a}^{-1}, 1000-2500$ $\mathrm{t} \cdot \mathrm{hm}^{-2} \cdot \mathrm{a}^{-1}, \quad 2500-5000 \quad \mathrm{t} \cdot \mathrm{hm}^{-2} \cdot \mathrm{a}^{-1}, \quad 5000-8000 \mathrm{t} \cdot \mathrm{hm}^{-2} \cdot \mathrm{a}^{-1}$, 8000-15000 $\mathrm{t} \cdot \mathrm{hm}^{-2} \cdot \mathrm{a}^{-1},>15000 \mathrm{t} \cdot \mathrm{hm}^{-2} \cdot \mathrm{a}^{-1}$, respectively. The percentage of change area in different degree during 2000-2005, 2005-2010 and 2000-2010 showed in Figure.5.
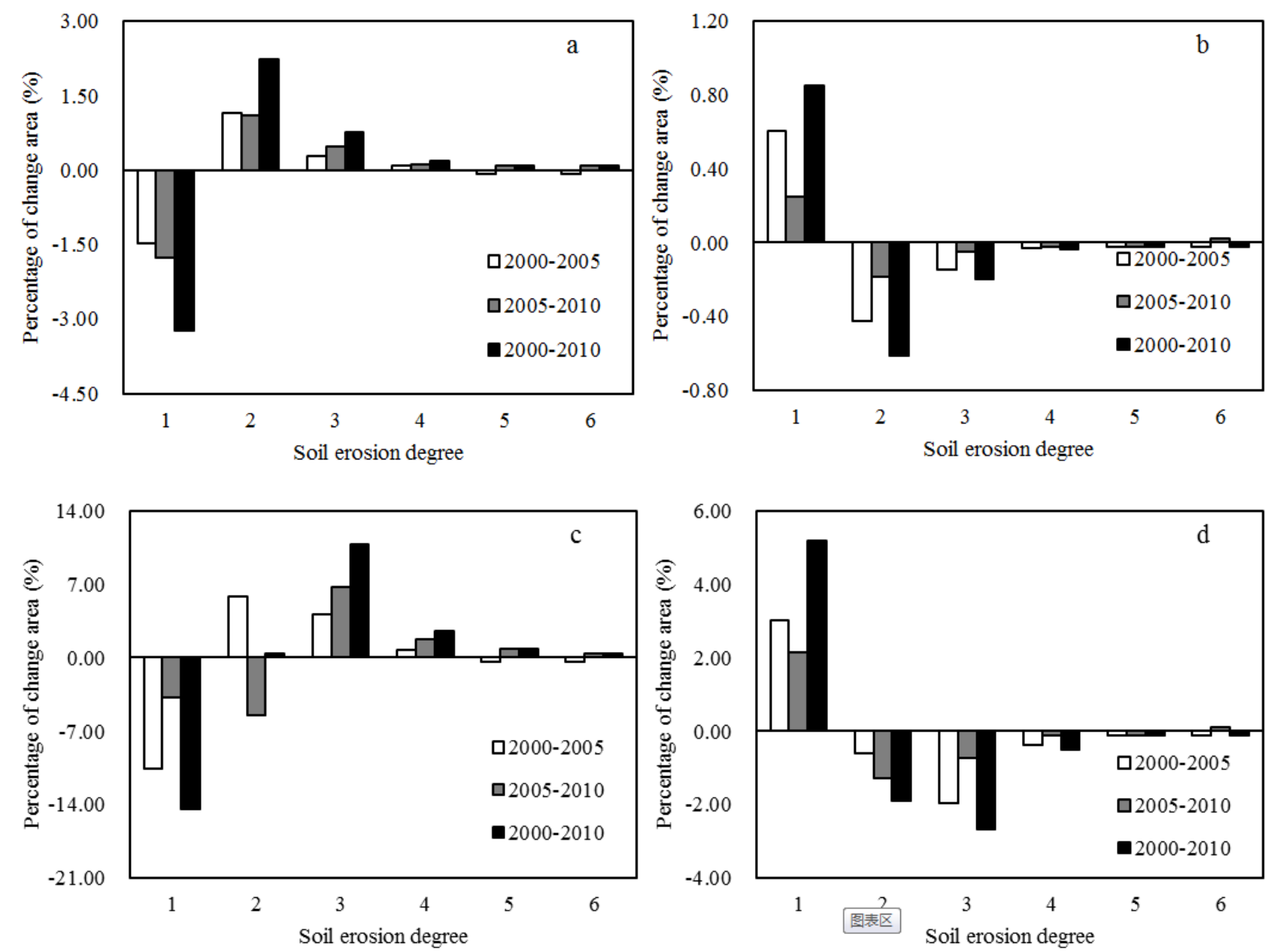

$1,<1000 \mathrm{t} \cdot \mathrm{hm}^{-2} \cdot \mathrm{a}^{-1} ; 2,1000-2500 \mathrm{t} \cdot \mathrm{hm}^{-2} \cdot \mathrm{a}^{-1} ; 3,2500-5000 \mathrm{t} \cdot \mathrm{hm}^{-2} \cdot \mathrm{a}^{-1} ; 4,5000-8000 \mathrm{t} \cdot \mathrm{hm}^{-2} \cdot \mathrm{a}^{-1} ; 5,8000-15000 \mathrm{t} \cdot \mathrm{hm}^{-2} \cdot \mathrm{a}^{-1} ; 6,>15000 \mathrm{t} \cdot \mathrm{hm}^{-2} \cdot \mathrm{a}^{-1} \cdot \mathrm{a}$ and c were calculated by rainfall erosivity in 2000, 2005 and 2010, while b and d were recalculated by rainfall erosivity in 2000 .

Figure 5. Change area of different soil erosion degree in the area of northern Shaanxi $(a, b)$ and the area of slope $>25^{\circ}(c, d)$.

The percentage of change area of northern Shaanxi in 1 degree was decrease with $3.23 \%$, while other degrees were increase with $2.24 \%, 0.76 \%, 0.18 \%$, and $0.06 \%$ in $2,3,4,5$ degree, respectively, and the percentage of change area in 6 degree was not obviously from 2000 to 2010 (Figure.5a). When recalculated by rainfall erosivity in 2000, the percentage of change area of northern Shaanxi in 1 degree was increase with $0.85 \%$, while other degrees were decrease with $0.61 \%, 0.20 \%, 0.04 \%$ and $0.01 \%$, respectively, and the percentage of change area in 6 degree was also not obviously from 2000 to 2010 (Figure.5b).

The percentage of change area in slope $>25^{\circ}$ of 1 degree was decrease with $14.46 \%$, while other degrees were increase with $0.31 \%, 10.83 \%, 2.52 \%$ and $0.80 \%$, respectively, and the percentage of change area in 6 degree was not obviously from 2000 to 2010 (Figure.5c). When recalculated by rainfall erosivity in 2000 , the percentage of change area in 1 degree was increase with $5.17 \%$, while other degrees were decrease with $1.89 \%, 2.70 \%, 0.51 \%$ and $0.07 \%$, respectively, and the percentage of change area in 6 degree was also not obviously 
from 2000 to 2010 (Figure.5d).

Overall, the change area of soil erosion in northern Shaanxi and slope $>25^{\circ}$ was decrease in 1 degree, while was increase in other degrees from 2000 to 2010 . When recalculated by rainfall erosivity in 2000 , the change area of soil erosion in northern Shaanxi and slope $>25^{\circ}$ was increase in 1 degree, while was decrease in other degrees from 2000 to 2010 . Vegetation cover change induced by GGP was reduce soil erosion, but due to rainfall erosivity increased, soil erosion was show increase trend in northern Shaanxi and slope $>25^{\circ}$ area.

\section{Conclusions}

As an important ecological construction and protection policy, the implementation of GGP has played important role in ecological environment. In this paper, the impact of GGP on soil erosion was evaluated by land use, MODIS NDVI, DEM, precipitation, and vegetation cover data in northern Shaanxi and the area of slope $>25^{\circ}$. Result showed:

(1) GGP implementation in northern Shaanxi was mainly during 1999-2003 and the area of returning farmland in the period accounted for $81.28 \%$ of the total area from 1999 to 2008.

(2) Farmland in northern Shaanxi was decrease largely with $3948.16 \mathrm{~km}^{2}$, while grassland was increase largely with $3229.71 \mathrm{~km}^{2}$. The percentage of change area of farmland and grassland was $4.94 \%$ and $4.04 \%$, respectively. The process of decreasing farmland and increasing grassland was mainly from 2000 to 2005. Farmland in the area of slope $>25^{\circ}$ was decrease largely with $270.67 \mathrm{~km}^{2}$, while grassland was increase largely with $226.90 \mathrm{~km}^{2}$. The percentage of change area of farmland and grassland was $4.84 \%$ and $4.05 \%$, respectively. The process of decreasing farmland and increasing grassland was mainly from 2000 to 2005, too.

(3) Farmland was convert into woodland and grassland from 2000 to 2010, which leaded to vegetation NDVI increase. Especially, the vegetation NDVI value of farmland in slope $>25^{\circ}$ was increase larger than whole area of northern Shaanxi.

(4) The area of soil erosion in northern Shaanxi and slope $>25^{\circ}$ was decrease in 1 degree, while was increase in other degrees from 2000 to 2010 . When recalculated by rainfall erosivity in 2000 , the area of soil erosion in northern Shaanxi and slope $>25^{\circ}$ was increase in 1 degree, while was decrease in other degrees from 2000 to 2010 . Vegetation cover change induced by GGP was reduce soil erosion, but due to rainfall erosivity increased, soil erosion showed increasing trend in northern Shaanxi and the area of slope $>25^{\circ}$.

This paper has many limitations. One of the limitations is soil erosion model with not detailed analysis in the process of research, but it is an important element. There are many methods and models to calculate rainfall erosivity, soil erodibility, topographical factor, vegetation cover factor and erosion control practice factor. Different choice of methods and models would produce different result in soil erosion. Moreover, the paper only estimated macro-scale soil erosion influenced by GGP in northern Shaanxi, but the results lack of validation by hydrological sediment monitoring data. So soil erosion model and results validation need to further be improved.

\section{Acknowledgements}

This work was supported by the National Natural Science Foundation of China (41271103), Cultivation Foundation of Xi'an University of Science and Technology (2014007), Provincial Natural Science Foundation of Science and Technology Department in Shaanxi (2015JQ4110), and Provincial Science Foundation of Department of Education in Shaanxi (14JK1479).

\section{References}

[1] State Forestry Administration of PRC, "2011 Statistical Yearbook of National Forestry Analysis Report." China Forestry Network, http://www.forestry.gov.cn. 2011.

[2] M. Persson, J. Moberg, M. Ostwald, J. Xu, "The Chinese Grain for Green programme: assessing the carbon sequestered via land reform.” Journal of Environment Management Vol. 126, pp. 142-146, 2013.

[3] H. Zhou, A. Van Rompaey, J. Wang, "Detecting the impact of the "Grain for Green" program on the mean annual vegetation cover in the Shaanxi province, China using SPOT-VGT NDVI data." Land Use Policy Vol. 26, pp. 954-960, 2009.

[4] J. J. Zhang, F. J. Chen, J. Q. Bai, X. P. Zhang, Y. N. Lei, E. J. Liu, "Evolution analysis of cultivated land structure characteristics on gully area of loess plateau in 1983-2009." Transactions of the CSAE Vol. 28(16), pp. 232-239, 2012.

[5] R. Chen, C. Ye, Y. Cai, X. Xing, Q. Chen, "The impact of rural out-migration on land use transition in China: past, present and trend." Land Use Policy Vol. 40, pp. 101-110, 2014.

[6] D. Li, J. Zhuo, Z. Sun, "Monitoring the effects of ecosystem restructuring project after returning farmland to forest based on RS and GIS." Transactions of the CSAE Vol. 24(12), pp. 120-126, 2008.

[7] Z. Li, B. Li, "Spatial and temporal changes in grain production before and after implementation of Grain for Green project in Loess Plateau region." Transactions of the CSAE Vol. 28(11), pp. 1-8, 2012.

[8] S. Cao, C. Xu, L. Chen, X. Wang, "Attitudes of farmers in China's northern Shaanxi province towards the land-use changes required under the Grain for Green Project, and implication for the project's success." Land Use Policy Vol.26, pp. 1182-1194, 2009.

[9] L. Chen, Z. Huang, J. Gong, B. Fu, Y. Huang, "The effect of land cover/vegetation on soil water dynamic in the hilly area of the loess plateau, China." Catena Vol. 70, pp. 200-208, 2007.

[10] P. Zhou, O. Luukkanen, T. Tookola, J. Nieminen, "Effect of vegetation cover on soil erosion in a mountainous watershed." Catena Vol. 75, pp. 319-325, 2008.

[11] Z. M. Wen, B. G. Less, F. Jiao, W. N. Lei, H. J. Shi, "Stratified vegetation cover index: a new way to assess vegetation impact on soil erosion." Catena Vol. 83, pp. 87-93, 2010. 
[12] Y. N. Zeng, W. P. Jin, H. M. Li, L. X. Tan, "Analysis and evaluation of cultivated land decrease in eastern part of Qinghai Plateau." Transactions of the CSAE Vol. 29(21), pp. 214-222, 2013.

[13] Shaanxi Bureau of Statistics, NBS Survey Office in Shaanxi, "Shaanxi statistical yearbook." China Statistics Press, Beijing. 2000-2009.

[14] D. Yoder, J. Lown, "The future of RUSLE: inside new revised universal soil loss equation." Journal of Soil and Water Conservation Vol. 50(5), pp. 484-489, 1995.

[15] W. B. Zhang, Y. Xie, B. Y. Liu, "Rainfall erosivity estimation using daily rainfall amounts." Scientia Geographica Sinica Vol. 22(6), pp. 705-711, 2002.

[16] W. B. Zhang, J. S. Fu, "Rainfall erosivity estimation under different rainfall amount." Resources Science Vol. 25(1), pp. 35-41, 2003.

[17] Y. Xie, B. Y. Liu, W. B. Zhang, "Sutdy on standard of erosion rainfall." Journal of Soil and Water Conservation Vol. 14(4), pp. 6-11, 2000.

[18] K. Auerswald, P Fiener, W. Martin, D. Elhaus, "Use and misuse of the $\mathrm{k}$ factor equation in soil erosion modelling: an alternative equation for determining USLE nomograph soil erodibility values." Catena Vol. 118, pp. 220-225, 2014.

[19] L. S. Zhao, X. L. Liang, F. Q. Wu, "Soil surface roughness change and its effect on runoff and erosion on the loess plateau of China." Journal of Arid Land Vol. 6(4), pp. 400-409, 2014.
[20] United States Department of Agriculture, "EPIC-erosion/productivity impact calculator: 1. Model Documentation." Technical Bulletin Number 1768. Washington, D C: USDA-ARS, 1990.

[21] W. H. Wischmeier, D. D. Smith, "Predicting rainfall erosion losses: a guide to conservation planning with universal soil loss equation (USLE).” Agriculture Handbook 537. Washington, D C: USDA-ARS, 1978.

[22] D. K. McCool, L. C. Brown, G. R. Foster, L. D. Meyer, "Revised slope steepness factor for the universal soil loss equation.” Transaction of the ASAE Vol. 30(5), pp. 1387-1396, 1987.

[23] B. Liu, M. A. Nearing, L. M. Risse, "Slope gradient effects on soil loss for steep slopes." Transactions of the ASAE Vol. 37(6), pp.1835-1840, 1994.

[24] S. M. DeJong, "Applications of reflective remote sensing for land degradation studies in a Mediterranean environment." Koninklijk Nederlandse Aardrijksunding Genootschap, 1994.

[25] T. Li, L. Zheng, "Soil erosion changes in the Yanhe watershed from 2001 to 2010 based on RUSLE model." Journal of Natural Resources Vol. 27(7), pp. 1164-1175, 2012.

[26] A. Lufafa, M. M. Tenywa, M. Isabirye, "Prediction of soil erosion in a Lake Victoria basin catchment using GIS based universal soil loss model." Agricultural Systems Vol.76, pp. 883-984, 2003.

[27] The Ministry of Water Resources of PRC (MWR of PRC), "SL190-2007 Standards of classification of soil erosion." Beijing: China Water \& Power Press, 2007. 